\title{
Informational Modeling the Intelligence of Buildings
}

\section{Andrey Volkov ${ }^{1, a}$, Pavel Chelyshkov ${ }^{1, b}$, Artem Sedov $^{1, \mathrm{c}}$, Anna Doroshenko ${ }^{1, \mathrm{~d}^{*}}$ and Denis Lysenko, e}

\author{
${ }^{1}$ Moscow state university of civil engineering, 129337, Russia, Moscow, Yaroslavskoe shosse 26 \\ a rector@mgsu.ru, bchelyshkovpd@gmail.com, csedov.eit@gmail.com, dpochta.avd@gmail.com, \\ edenis.lysenko111@gmail.coml \\ *The corresponding author
}

\begin{abstract}
Keywords: Engineering systems; Buildings intelligence; Consuming in building; Thermal and mass transfer automated monitoring.
\end{abstract}

\begin{abstract}
In this article considered the principle of process definition measurement of engineering systems when evaluating buildings intelligence. Suggested method provides objective nature of estimates based solely on quantitative indicators of energy resources consumption. Intelligence coefficient of building is the higher the more amount of processes controlling the change of values of observable parameters of building are functionally adaptive to it's own conditions area. Such approach avoids the subjectivity of expert estimates and operates only with objective values of material and energetic costs when determining measures of a process. In turn, an objective assessment of measures of processes of changing status can save an objective nature of assessment of intelligence of the building. This article was performed within the Russian State task.
\end{abstract}

\section{Introduction}

Intelligence of buildings as it shown on [1] is not an abstract concept but the value liable to objective numerical assessment. For such purpose used an approach consisted of taking the coefficient of intelligence of building as a ratio of the measure of processes controlling the change of observable parameters of building that are functionally adaptive to its own conditions area to the measure of all processes controlling the change of values of observable parameters of building.

Coefficient of intelligence of building is the higher the bigger amount of processes controlling the value changing of observable parameters of building are functionally adaptive to its own conditions area [2-4].

Leaving outside of this article consideration of rules attributing a specific process to a particular set, let us consider the definition of process measure and calculations of such measures.

Three types of energetic resources are consuming in building: the heat, the water and the electricity. Thus, all the processes of changing the state parameters of building could be divided as thermal and mass transfer [5-10].

When defining the process measure two conditions must be met: universality, additivity.

The first condition involves the ability to compare processes containing energy sources of different nature. Since the intelligence of building is evaluated with respect to all of the processes without differentiation by groups, you must use the measurement equally suitable for the processes consuming heat energy and for the processes consuming (or producing) electricity. Such measure is a ton of equivalent fuel. Translation onto tons of equivalent fuel (t. e. f.) is carried out for heat as $1 \mathrm{Gcal}=$ 0.1486 t. e. f. and for electricity as $1000 \mathrm{kWh}=0.3445$ t. e. f.

The second condition - additivity - must be observed to simplify the mathematical calculations, because in this case the aggregate measure of the processes used in the calculation of intelligence coefficient is obtained as the simple arithmetic sum of the measures of each process. This, in turn, simplifies the algorithm and enhances the performance of automatic calculations and mathematical models. 


\section{Method}

In compliance with the conditions described for the determination of the measures of processes changing the parameters of building composed expression (1). Here measure of each process is defined as the sum of energetic $\left(c^{E}\right)$ and material $\left(c^{M}\right)$ measures of this process.

$$
c=c^{E}+c^{M}
$$

Energetic measure of heat exchange processes is calculating by this formula:

$$
c^{E}=\frac{E_{i}}{\sum_{i=1}^{n} E_{i}}
$$

$E_{i}$ - energetic capacity of this process for the adopted period of time, tons of equivalent fuel (t. e.

f.).; $\sum_{i=1}^{n} E_{i}$ - total energetic capacity of all heat processes in observing building, t. e. f.

Material processes measure is calculated as follows:

$$
c^{M}=\frac{M_{i}}{\sum_{i=1}^{n} M_{i}}
$$

$M_{i}$ - material capacity of this process for the adopted period of time, thousand $\mathrm{Kg}$.; $\sum_{i=1}^{n} M_{i}$ - total material capacity of all mass transfer processes in observing building for the adopted period of time, thousand $\mathrm{Kg}$.

Thus, quantitative expression of the significance of each process (cr) is a relative dimensionless weight coefficient characterizing the share of this process in the overall balance of heat and mass transfer processes of changing the state of parameters of building.

Next, consider the direct process of changing the state of the building parameters and expressions to determine their measures.

As part of the research by now considered 40 engineering systems, in which highlighted 79 processes of changing the state of the building parameters. For each process were composed the expressions to determine its material capacity.

As an example, let us consider in general terms the definition of measures changes in the state building process parameters in the system ventilation with heat recovery and air conditioning.

Such system contain the following processes of changing the state building process parameters: air supply, air intake, air heating, recuperation, air cooling, humidification.

The process of air supply requires electricity consumption, whose volume of consumption is determined by the expression (4).

$$
E_{\text {air }}^{e l}=\frac{G_{a i r} \cdot H}{\eta} \cdot 0,34 \cdot 10^{-6}
$$

Where $E_{a i r}^{e l}$ - electrical energy, required for air supply, t.e.f.; $G_{a i r}$ - hour volume of air intake, m3; $H$ - pressure, created by the fan, $\mathrm{Pa} ; \eta$ - efficiency of the fan.

Energetic capacity of the process of air supply is equal to $E_{\text {air }}^{e l}$; Material capacity is equal to zero.

Similarly, determined energy and material capacity of other listed processes. Further, the known energy and material capacities of each process, in accordance with the expressions (2) and (3) are 
defined the material and energy measures of processes and further by the expression (1) determined measures of processes.

\section{Conclusion}

Thus, the above discussed method for determining measures of processes of change in the state of the building parameters, allowing to carry out a numerical estimate of the effect of each engineering system on the measure of building intelligence. The present approach avoids the subjectivity of expert assessments, operating only with objective values of material and energetic cost in measure determination. In turn, an objective assessment of the state change process measures can save an objective nature of the intelligence of building.

\section{Acknowledgements}

This work was financially supported by the Ministry of Russian Education (state task \#2014/107)

\section{References}

[1] Volkov A., Sedov A., Chelyshkov P. Usage of building information modelling for evaluation of energy efficiency // Applied Mechanics and Materials. 2013. T. 409-410. C. 630-633.

[2] Crosbie, T., Dawood, N., Dean, J. Energy profiling in the life-cycle assessment of buildings (2010) Management of Environmental Quality, 21 (1), pp. 20-31.

[3] Doukas, H., Patlitzianas, K.D., Iatropoulos, K., Psarras, J. Intelligent building energy management system using rule sets (2007) Building and Environment, 42 (10), pp. 3562-3569.

[4] Dounis, A.I., Caraiscos, C. Advanced control systems engineering for energy and comfort management in a building environment-A review (2009) Renewable and Sustainable Energy Reviews, 13 (6-7), pp. 1246-1261.

[5] Elliott, C. Intelligent buildings: Systems engineering for the built environment (2009) Intelligent Buildings International, 1 (1), pp. 75-81.

[6] Volkov, A. General information models of intelligent building control systems: Scientific problem and hypothesis (2014) Advanced Materials Research, 838-841, pp. 2969-2972.

[7] Volkov, A. General information models of intelligent building control systems: Basic concepts, determination and the reasoning (2014) Advanced Materials Research, 838-841, pp. 2973-2976.

[8] Volkov, A.A., Sedov, A.V., Chelyshkov, P.D. Modelling the thermal comfort of internal building spaces in social buildings (2014) Procedia Engineering, 91, pp. 362-367.

[9] Volkov, A., Latyshev, K. Intelligent and complex monitoring in intelligent buildings (2014) Applied Mechanics and Materials, 580-583, pp. 3204-3207.

[10] Andrey, V. Building intelligence quotient: Mathematical description (2013) Applied Mechanics and Materials, 409-410, pp. 392-395. 